\title{
Pharmacokinetics of a Single Dose of Azilsartan in Pediatric Patients: A Phase 3, Open-Label, Multicenter Study
}

\author{
Kazuaki Enya - Ben T. Saji - Takuya Kato - Hiroyuki Okamoto • \\ Emiko Koumura
}

Received: May 11, 2018 / Published online: July 19, 2018

(c) The Author(s) 2018

\section{ABSTRACT}

Introduction: Azilsartan is an angiotensin II receptor blocker indicated for the treatment of patients with hypertension. The efficacy and safety of azilsartan are established in adults, but have not been evaluated in pediatric patients, nor has its pharmacokinetic profile been determined in pediatric patients.

Methods: In this phase 3, open-label, multicenter study, we investigated the pharmacokinetics and safety of single doses of azilsartan in six Japanese patients with hypertension, aged 9-14 years. The dose of azilsartan was $5 \mathrm{mg}$ for three patients weighing less than $50 \mathrm{~kg}$, with mean body weight at baseline of $27.5 \mathrm{~kg}$, and

Ben T. Saji: Deceased.

Enhanced digital features To view enhanced digital features for this article go to https://doi.org/10.6084/ m9.figshare.6791990.

K. Enya $(\bowtie) \cdot$ E. Koumura

Japan Development Center, Takeda Pharmaceutical Co. Ltd, Osaka, Japan

e-mail: kazuaki.enya@takeda.com

B. T. Saji

First Department of Pediatrics, Toho University

Omori Medical Center, Tokyo, Japan

T. Kato $\cdot$ H. Okamoto

Formerly Japan Development Center, Takeda

Pharmaceutical Co. Ltd, Osaka, Japan
$10 \mathrm{mg}$ for three patients weighing at least $50 \mathrm{~kg}$, with mean body weight at baseline of $65.9 \mathrm{~kg}$.

Results: Mean maximum plasma concentration $\left(C_{\max }\right)$ of azilsartan was 888.3 and $831.3 \mathrm{ng} / \mathrm{mL}$ and median time to maximum concentration $\left(T_{\max }\right)$ of unchanged azilsartan was 3.0 and $4.0 \mathrm{~h}$, in the $5-\mathrm{mg}$ and $10-\mathrm{mg}$ groups, respectively. Mean areas under the plasma concentration-time curve (AUC) from $0-24 \mathrm{~h}$ post-dose $\left(\mathrm{AUC}_{0-24}\right)$ and $0 \mathrm{~h}$ to infinity $\left(\mathrm{AUC}_{0-\mathrm{inf}}\right)$ were 6350.3 and $6635.7 \mathrm{ng} \mathrm{h} / \mathrm{mL}$, respectively, in the 5-mg group, and 6871.7 and $7433.3 \mathrm{ng} \mathrm{h} / \mathrm{mL}$, respectively, in the $10-\mathrm{mg}$ group. Both doses were well tolerated; no treatment-emergent adverse events considered to be related to azilsartan occurred during the study.

Conclusion: Our data suggest that pediatric patients weighing less than $50 \mathrm{~kg}$ may have approximately 2 -fold greater exposure to azilsartan than those weighing at least $50 \mathrm{~kg}$ at the same dose. Exposure to azilsartan in children weighing at least $50 \mathrm{~kg}$ is comparable to that in healthy adults at the same dose.

Trial Registration: ClinicalTrials.gov identifier, NCT02451150.

Funding: Takeda Pharmaceutical Co. Ltd.

Keywords: Angiotensin II receptor blocker; Azilsartan; Cardiology; Hypertension; Pediatric; Pharmacokinetics 


\section{INTRODUCTION}

Although hypertension is usually considered as a disorder mainly affecting middle-aged and older patients, children and adolescents are also at risk of developing the condition [1]. In fact, the incidence of pediatric hypertension appears to be increasing [2], with up to $5 \%$ of children and adolescents in the USA and $0.1-3 \%$ in Japan estimated to have high blood pressure $[1,3]$.

Pediatric hypertension is not typically associated with immediate death or cardiovascular complications [4]; however, hypertension persisting from childhood is likely to lead to development of cardiovascular disease and progression of organ damage, including renal dysfunction, thereby markedly affecting the patient's quality of life and prognosis, both in childhood and in the future. Therefore, it is crucial to manage high blood pressure at an early stage, as recommended by the current Japanese Society of Hypertension guidelines [1]. In Japan, four drugs are currently approved for the management of hypertension in pediatric patients, namely enalapril (indicated for patients at least 1 month of age), lisinopril (at least 6 years), valsartan (at least 6 years), and amlodipine (at least 6 years), despite a wider range of drugs being approved for use in adult patients [1]. Thus, compared with adults, treatment options for pediatric patients are somewhat limited, predominantly because of a paucity of data in this population.

Azilsartan (TAK-536) is an angiotensin II receptor blocker (ARB) approved for the treatment of adult hypertension in Japan in January 2012. In adults, azilsartan is considered superior to the ARBs candesartan cilexetil and olmesartan medoxomil in terms of its ability to lower 24-h blood pressure, alongside a favorable safety profile $[5,6]$. Although there are some exceptions, previously reported clinical trials of ARBs indicate that their blood pressure (BP)-lowering effects in children are consistent with their effects in adults $[7,8]$. Given these findings, it may be a useful agent for the treatment of hypertension in pediatric patients. However, to date, azilsartan has not been evaluated in
Japanese pediatric patients, particularly in terms of its pharmacokinetic profile.

Previous pharmacokinetic studies of azilsartan in healthy adults showed dose-linear parameters; peak plasma concentrations of azilsartan were reached between 1.8 and $2.4 \mathrm{~h}$ after oral dosing, with an elimination half-life $\left(T_{1 / 2}\right)$ of approximately $13 \mathrm{~h}$ [9]. Azilsartan is eliminated both through renal clearance (approximately $2.3 \mathrm{~mL} / \mathrm{min}$ ) and hepatic metabolism, with no clinically relevant changes in azilsartan exposure observed in patients with mild-to-severe renal impairment or mild-tomoderate hepatic impairment [10-13]. The principal metabolite of azilsartan formed by $O$-dealkylation via the cytochrome P450 2C9 isoform is M-II, and the main minor metabolite, which is formed by decarboxylation, is M-I; both are pharmacologically inactive $[10,13]$. A phase 1 study by Webb et al. investigated the pharmacokinetics of azilsartan medoxomil in healthy adults and in children with hypertension aged 4-16 years [14], by developing a population pharmacokinetic model to evaluate the application of body weight-adjusted azilsartan medoxomil tablet doses used in pediatric patients. It was found that body weight is the primary factor affecting azilsartan pharmacokinetic parameters [14].

This study was therefore designed to further analyze the pharmacokinetics and safety of a single oral dose of azilsartan specifically in pediatric patients with hypertension, to serve as a basis for further development of azilsartan in this population in Japan.

\section{METHODS}

\section{Study Design}

This was an open-label, phase 3 , multicenter study (ClinicalTrials.gov NCT02451150) to analyze the pharmacokinetics and safety following a single oral dose of azilsartan in pediatric patients aged from 6 to younger than 16 years with hypertension. This study comprised a 28-day run-in period, a 1-day treatment period, and follow-up at 6 and 15 days posttreatment. During the run-in period, patients 
underwent screening and physical examinations, including blood pressure measurement and resting 12-lead ECG. Patients entered the hospital on the last day of the run-in period and were discharged at the end of the treatment period unless continued hospitalization for medical care was required. Patients received a single oral dose of azilsartan, in the form of a single tablet: $5 \mathrm{mg}$ for patients weighing less than $50 \mathrm{~kg}$, or $10 \mathrm{mg}$ for patients weighing at least $50 \mathrm{~kg}$ based on the modeling and simulation of azilsartan exposure [14]. Doses were taken with water following breakfast, and patients were assessed daily from the day prior to drug administration until deemed necessary.

\section{Patient Population}

Patients were enrolled at three centers in Japan and were required to be aged from 6 to younger than 16 years, to have a diagnosis of hypertension per Japanese Circulation Society guidelines [15] (sitting diastolic or systolic blood pressure in at least the 95th percentile for essential hypertension; in at least the 90th percentile for secondary hypertension), to weigh at least $20 \mathrm{~kg}$ during the run-in period, and to be able to take the tablets of the study drug. Patients who had undergone renal transplant were eligible to participate in the study if the transplantation had taken place more than 6 months prior to the study and the graft was stable.

Patients were excluded if they had received any study drug within 30 days prior to run-in, or were involved in another clinical or postmarketing study; had poorly controlled hypertension; were diagnosed with malignant or accelerated hypertension; had severe renal dysfunction, renal neovascular disease, severe nephrotic syndrome not in remission, were receiving dialysis, or had a serum albumin concentration of less than $2.5 \mathrm{~g} / \mathrm{dL}$; had a history of, or the signs or symptoms of, serious cardiovascular, hepatobiliary, gastrointestinal, endocrinological, hematological, immunological, urinogenital, or psychiatric disease, cancer, or any other disease that had adversely affected the patient's health; had glycated hemoglobin (HbA1c) greater than 9\%; had hyperkalemia exceeding the upper limit of normal $(4.7 \mathrm{mEq} / \mathrm{L})$; or had a known hypersensitivity or allergy to ARBs.

Written, informed consent was received from the patients' parent/guardian and patients if possible before the start of the study. The study was conducted in compliance with the institutional review board (IRB) regulations stated in the Good Clinical Practice (GCP) guidelines, and all applicable local regulations. The ethical conduct of the study was in line with the Declaration of Helsinki and the International Conference on Harmonisation (ICH) Harmonised Tripartite Guideline for GCP E6, and all applicable laws and regulations. The protocol and other study-related documents were reviewed and approved by the IRB of the study site.

\section{Bioanalytical Method}

One blood sample $(2 \mathrm{~mL})$ was obtained predose and at $1,2,3,4,6,8$, and $24 \mathrm{~h}$ post-dose; where possible, catheters were used to avoid repeated use of a needle. Blood samples were collected into chilled tubes containing the potassium salt of ethylenediaminetetraacetic acid. Plasma was separated by centrifugation and samples stored at approximately $-20^{\circ} \mathrm{C}$ or lower. Total urine collections were made at pre-dose (single collection between -12 and $0 \mathrm{~h}$ ) and at $0-4,4-8$, $8-12$, and $12-24 \mathrm{~h}$ post-dose. Urine samples were stored as 1-mL aliquots at approximately $-20{ }^{\circ} \mathrm{C}$ or lower. Concentrations of azilsartan, $\mathrm{M}-\mathrm{I}$, and $\mathrm{M}-\mathrm{II}$ in plasma and urine were determined using validated liquid chromatography-tandem mass spectrometry assays at CMIC Laboratories, Nishiwaki, Japan [16]. For both the plasma and urine samples, $0.8 \mathrm{~mol} / \mathrm{L}$ hydrochloric acid $(20 \mu \mathrm{L})$ and methanol with internal standard $(25 \mu \mathrm{L})$ were added to $100-\mu \mathrm{L}$ samples for protein precipitation, followed by the addition of $0.1 \mathrm{mmol} / \mathrm{L}$ ammonium acetate buffer ( $\mathrm{pH} 4.0 ; 500 \mu \mathrm{L}$ ). The samples were then subjected to standard extraction and purification procedures prior to analysis. Liquid chromatography separation was performed using an XTerra $\mathrm{RP}_{18}$ column (Waters; particle size $5 \mu \mathrm{m}$, $2.1 \times 250 \mathrm{~mm}$ ). The mobile phase consisted of 
acetonitrile/distilled water/acetic acid in a 60:40:0.05 (v/v/v) ratio and the sample was pumped through the column at $0.2 \mathrm{~mL} / \mathrm{min}$. For detection, an API4000 mass spectrometer (AB Sciex, Framingham, MA, USA) with positive ion electrospray in multiple-reaction monitoring mode was employed. The LC-MS/MS assay range for the detection of azilsartan, M-I, and $\mathrm{M}-\mathrm{II}$ in plasma was $1-2500 \mathrm{ng} / \mathrm{mL}$. The range for detection of azilsartan, M-I, and M-II in urine was $20-10,000 \mathrm{ng} / \mathrm{mL}$.

\section{Pharmacokinetics}

Pharmacokinetic variables derived from azilsartan, M-I, and M-II concentrations in plasma included area under the plasma concentration-time curve from 0 to $24 \mathrm{~h}$ post-dose $\left(\mathrm{AUC}_{0-24}\right)$ and from $0 \mathrm{~h}$ to infinity $\left(\mathrm{AUC}_{0-\mathrm{inf}}\right)$; maximum observed concentration in plasma $\left(C_{\max }\right)$; time to reach $C_{\max }\left(T_{\max }\right)$; terminal elimination rate constant $(\lambda z=$ negative slope of the log-linear regression of the natural logarithm concentration-time curve during the terminal phase); terminal elimination half-life $\left(T_{1 / 2}=\ln (2) / \lambda z\right) ; \quad$ apparent clearance after extravascular administration $(\mathrm{CL} / F=$ dose/ $\left.\mathrm{AUC}_{0-\mathrm{inf}}\right)$; and apparent volume of distribution during the terminal phase $\left(V_{z} / F=[C L / F] / \lambda z\right)$. Urine pharmacokinetic parameters included total amount excreted in urine from 0 to $24 \mathrm{~h}$ post-dose $\left(\mathrm{Ae}_{\mathrm{O}-24}\right)$, fraction excreted in the urine $\left(\mathrm{Fe}=\left[\mathrm{Ae}_{0-24} /\right.\right.$ dose $\left.] \times 100\right)$, and renal clearance $\left(\mathrm{CLr}=\mathrm{Ae}_{0-24} / \mathrm{AUC}_{\mathrm{O}-24}\right)$. Fe estimates for azilsartan, M-I, and M-II were adjusted for molecular weight. The arithmetic mean cumulative urinary excretion ratios were calculated as percentage of dose (azilsartan equivalent) of azilsartan, M-I, M-II, and total (azilsar$\tan +\mathrm{M}-\mathrm{I}+\mathrm{M}-\mathrm{II})$ at $24 \mathrm{~h}$. Pharmacokinetic parameters were derived using noncompartmental methods via WinNonlin 6.3 (Pharsight Corp., Mountain View, CA, USA) for the plasma data and SAS version 9.2 (SAS Institute, Cary, NC, USA) for the urine data. Plasma and urine pharmacokinetic parameters for each cohort were summarized using descriptive statistics.

\section{Safety}

Safety was analyzed by recording all treatmentemergent adverse events (TEAEs) using the Medical Dictionary for Regulatory Activities terminology, Japanese edition version 18.0. Safety assessments included clinical laboratory tests; assessment of vital signs (body temperature, blood pressure, and pulse rate); electrocardiogram (ECG), and physical examinations in all patients who received at least one dose of study medication. Safety findings were summarized using descriptive statistics or frequency distributions.

\section{RESULTS}

\section{Patient Disposition and Baseline Characteristics}

A total of six patients signed the informed consent form and were enrolled in the study. All patients received the study drug. Three patients weighing less than $50 \mathrm{~kg}$ received azilsartan $5 \mathrm{mg}$ and three patients weighing at least $50 \mathrm{~kg}$ received azilsartan $10 \mathrm{mg}$. All patients completed the study.

Patient demographic and baseline characteristics are detailed in Table 1 . All patients had concurrent medical conditions classified under the system organ class "renal and urinary disorders". Mean age was 9.0 years (range 9-9 years) in the 5-mg group and 13.7 years (range 13-14 years) in the 10-mg group. Mean weight was $27.5 \mathrm{~kg}$ (range 22.4-33.4 kg) in the 5 -mg group and $65.9 \mathrm{~kg}$ (range $63.5-69.2 \mathrm{~kg}$ ) in the 10-mg group. One patient in the 10-mg group was deemed to have essential hypertension, while five patients were classified as having secondary hypertension. All patients took concomitant drugs during the study.

\section{Pharmacokinetics}

The time-course profiles for the plasma concentration of azilsartan and its metabolites following a single oral dose of azilsartan are presented in Fig. 1. Azilsartan was rapidly 
Table 1 Patient demographic and baseline characteristics (safety and pharmacokinetic analysis data set)

\begin{tabular}{|c|c|c|c|c|c|c|c|}
\hline \multirow{3}{*}{$\begin{array}{l}\text { Characteristic } \\
\text { Patient number }\end{array}$} & \multicolumn{6}{|c|}{ Dose } & \multirow[t]{3}{*}{ Total $(n=6)$} \\
\hline & \multicolumn{3}{|c|}{$5 \mathrm{mg}(n=3)$} & \multicolumn{3}{|c|}{$10 \mathrm{mg}(n=3)$} & \\
\hline & $\overline{1}$ & 2 & 3 & 4 & 5 & 6 & \\
\hline Age, years & 9 & 9 & 9 & 14 & 13 & 14 & \\
\hline Median (range) & & & & & & & $11(9-14)$ \\
\hline \multicolumn{8}{|l|}{ Gender, $n(\%)$} \\
\hline Male & & 1 & & & 1 & 1 & $3(50.0)$ \\
\hline Female & 1 & & 1 & 1 & & & $3(50.0)$ \\
\hline Height, $\mathrm{cm}$ & 142 & 130 & 121 & 155 & 166 & 169 & \\
\hline Median (range) & & & & & & & $148.5(121-169)$ \\
\hline \multicolumn{8}{|l|}{ Weight at baseline, $n(\%)$} \\
\hline$<50.0 \mathrm{~kg}$ & & & & & & & $3(50.0)$ \\
\hline$\geq 50.0 \mathrm{~kg}$ & & & & & & & $3(50.0)$ \\
\hline Weight at baseline, $\mathrm{kg}$ & 33.4 & 26.8 & 22.4 & 65.0 & 63.5 & 69.2 & \\
\hline Median (range) & & & & & & & $48.45(22.4-69.2)$ \\
\hline BMI at baseline, $\mathrm{kg} / \mathrm{m}^{2}$ & 16.6 & 15.9 & 15.3 & 27.1 & 23.0 & 24.2 & \\
\hline Median (range) & & & & & & & $19.80(15.3-27.1)$ \\
\hline \multicolumn{8}{|c|}{ Caffeine classification, $n(\%)$} \\
\hline Yes & & & & & & & $0(0)$ \\
\hline No & 1 & 1 & 1 & 1 & 1 & 1 & $6(100)$ \\
\hline \multicolumn{8}{|l|}{ Disease duration, years } \\
\hline Median (range) & & & & & & & $1.95(0.1-7.6)$ \\
\hline \multicolumn{8}{|c|}{ Types of hypertension, $n$ (\%) } \\
\hline Essential hypertension & & & & & & 1 & $1(16.7)$ \\
\hline Secondary hypertension & 1 & 1 & 1 & 1 & 1 & & $5(83.3)$ \\
\hline
\end{tabular}

$B M I$ body mass index

absorbed, being detectable in the plasma of all participants at $1 \mathrm{~h}$ post-dose. Similarly, plasma concentrations of M-I were also detectable in all patients at $1 \mathrm{~h}$ post-dose. M-II was detectable in plasma at $1 \mathrm{~h}(n=5)$ or $2 \mathrm{~h}(n=1 ; 10 \mathrm{mg}$ group $)$ following administration.

Pharmacokinetics for the six patients included in the study are shown in Table 2 . Median azilsartan $T_{\max }$ was $3 \mathrm{~h}$ (range $2.1-3.0 \mathrm{~h}$ ) in the 5 -mg group and $4 \mathrm{~h}$ (range $2.1-4.0 \mathrm{~h}$ ) in the 10-mg group, and mean azilsartan $C_{\max }$ was 888.3 and $831.3 \mathrm{ng} / \mathrm{mL}$, respectively. After reaching $C_{\max }$, the plasma concentration of azilsartan decreased, with a mean $T_{1 / 2}$ of $4.7 \mathrm{~h}$ in the 5-mg group and $6.1 \mathrm{~h}$ in the 10-mg group. In the 5-mg and 10-mg groups, mean azilsartan $\mathrm{AUC}_{0-24}$ was 6350.3 and $6871.7 \mathrm{ng} \mathrm{h} / \mathrm{mL}$, respectively, and mean $\mathrm{AUC}_{0-\text { inf }}$ was 6635.7 and $7433.3 \mathrm{ng} \mathrm{h} / \mathrm{mL}$, respectively. 


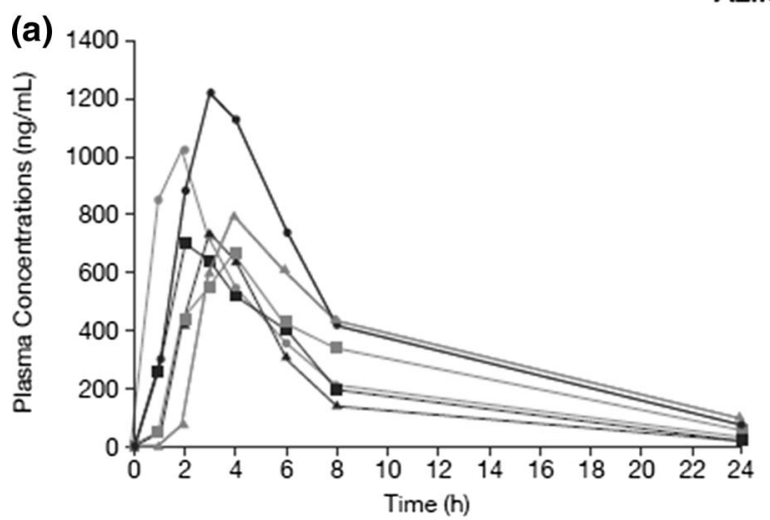

\section{Azilsartan}
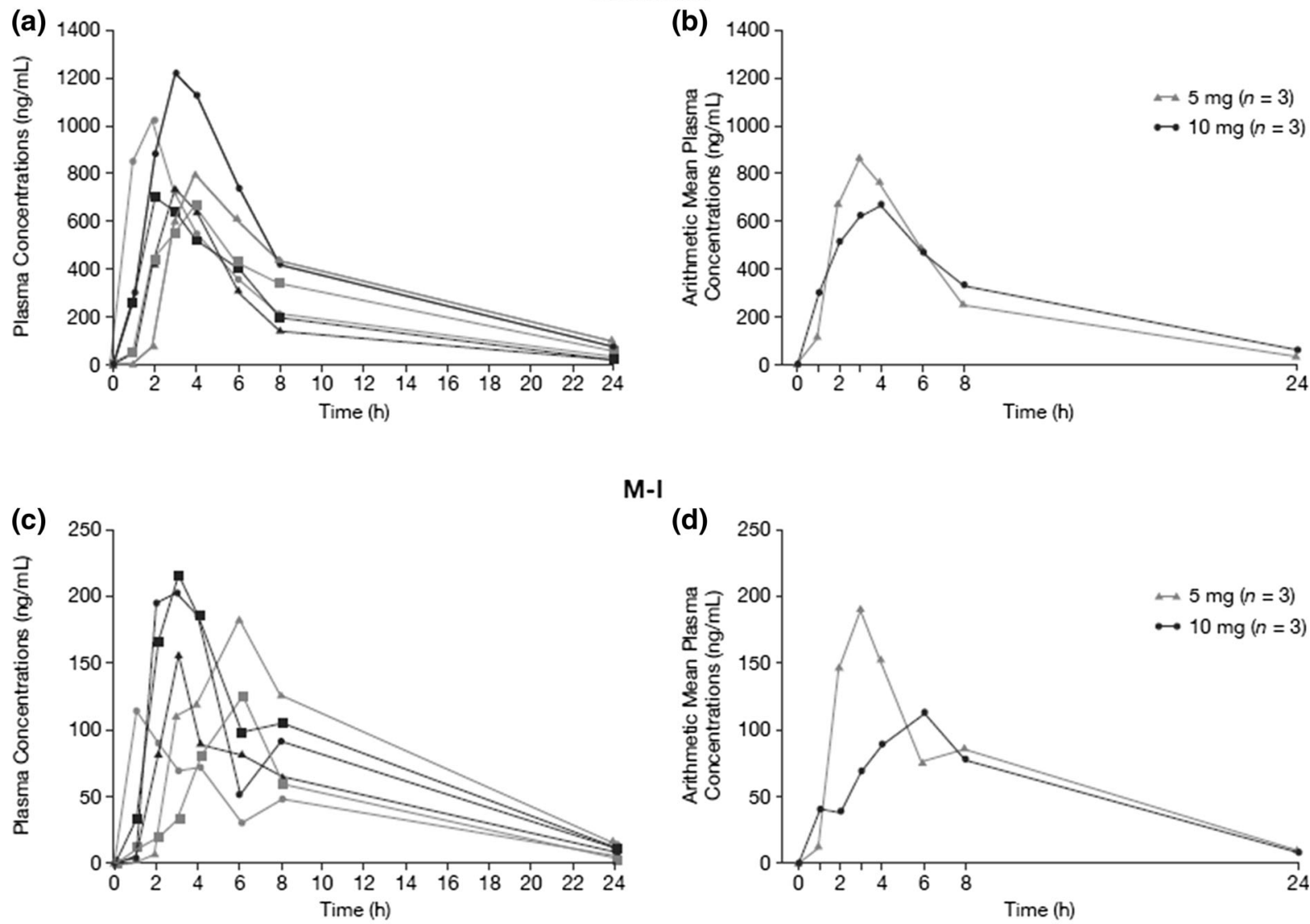

M-I
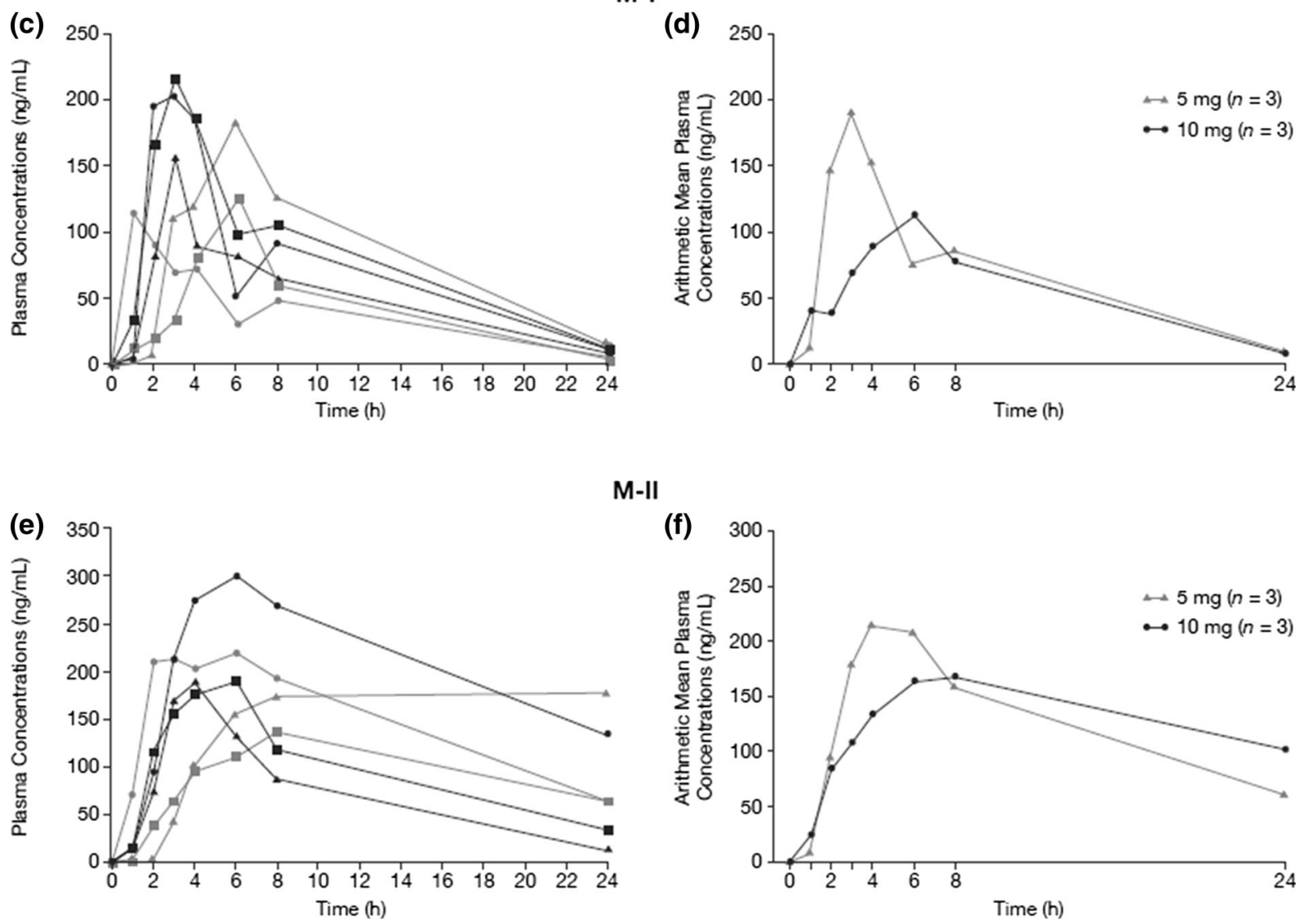

M-II

Fig. 1 Plasma concentrations of azilsartan (a, b), minor azilsartan metabolite (M-I) (c, d), and major azilsartan metabolite (M-II) (e, f) after a single oral dose of azilsartan $5 \mathrm{mg}$ (gray lines) or $10 \mathrm{mg}$ (black lines) in Japanese

For the M-I metabolite, both mean $\mathrm{AUC}_{0-24}$ (5 mg: $1592.7 \mathrm{ng} \mathrm{h} / \mathrm{mL} ; 10 \mathrm{mg}: 1420.5 \mathrm{ng} \mathrm{h} / \mathrm{mL}$ ) and $C_{\max } \quad(5 \mathrm{mg}: \quad 191.3 \mathrm{ng} / \mathrm{mL} ; \quad 10 \mathrm{mg}$ :

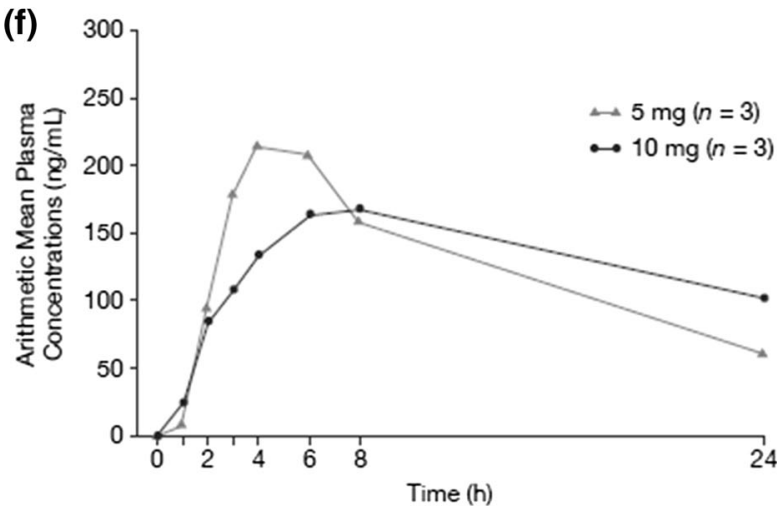

pediatric patients. Each line in a, $\mathbf{c}$, and $\mathbf{e}$ denotes a single patient; $\mathbf{b}, \mathbf{d}$, and $\mathbf{f}$ show arithmetic mean concentrations

$141.3 \mathrm{ng} / \mathrm{mL}$ ) were lower than those observed for azilsartan; similar results were observed for the M-II metabolite with $\mathrm{AUC}_{0-24}$ values of 
Table 2 Descriptive statistics of pharmacokinetic parameters of azilsartan after a single oral dose of azilsartan 5 or $10 \mathrm{mg}$ in Japanese pediatric patients

\begin{tabular}{|c|c|c|c|c|c|c|c|}
\hline \multirow{3}{*}{$\begin{array}{l}\text { Pharmacokinetic } \\
\text { parameter } \\
\text { Patient number }\end{array}$} & \multicolumn{6}{|l|}{ Dose } & \multirow{3}{*}{$\begin{array}{l}\text { Total }(n=6) \\
\text { Median (range) }\end{array}$} \\
\hline & \multicolumn{3}{|c|}{$5 \mathrm{mg}(n=3)$} & \multicolumn{3}{|c|}{$10 \mathrm{mg}(n=3)$} & \\
\hline & 1 & 2 & 3 & $\overline{4}$ & 5 & 6 & \\
\hline $\mathrm{AUC}_{0-24}, \mathrm{ng} \mathrm{h} / \mathrm{mL}$ & 4211 & 5107 & 9733 & 6280 & 7900 & 6435 & $6357.5(4211-9733)$ \\
\hline $\mathrm{AUC}_{0-\mathrm{inf}}, \mathrm{ng} \mathrm{h} / \mathrm{mL}$ & 4273 & 5254 & 10,380 & 6540 & 8833 & 6927 & $6733.5(4273-10,380)$ \\
\hline$C_{\max }, \mathrm{ng} / \mathrm{mL}$ & 736 & 705 & 1224 & 1025 & 802 & 667 & $769(667-1224)$ \\
\hline$T_{\max }, \mathrm{h}$ & 3.0 & 2.1 & 3.0 & 2.1 & 4.0 & 4.0 & $3.0(2.1-4.0)$ \\
\hline$T_{1 / 2}, \mathrm{~h}$ & 3.90 & 4.43 & 5.85 & 5.49 & 6.84 & 6.11 & $5.67(3.90-6.84)$ \\
\hline $\mathrm{CL} / F, \mathrm{~L} / \mathrm{h}$ & 1.17 & 0.952 & 0.482 & 1.53 & 1.13 & 1.44 & $1.15(0.482-1.53)$ \\
\hline$V_{\mathrm{z}} / F, \mathrm{~L}$ & 6.59 & 6.09 & 4.07 & 12.1 & 11.2 & 12.7 & $8.895(4.07-12.7)$ \\
\hline $\mathrm{Fe}, \%$ & 10.0 & 5.18 & 4.74 & 8.76 & 0.544 & 7.21 & $6.195(0.544-10.0)$ \\
\hline CLr, L/h & 0.119 & 0.0507 & 0.0244 & 0.139 & 0.00689 & 0.112 & $0.08135(0.00689-0.139)$ \\
\hline
\end{tabular}

Data shown are arithmetic means (standard deviations), unless otherwise stated

$A U C$ area under the plasma concentration-time curve, $C_{\text {max }}$ maximum plasma concentration, $C L / F$ oral clearance, $C L r$ renal clearance, $F e$ fraction excreted, $T_{\max }$ time to maximum concentration, $T_{1 / 2}$ half-life, $V_{z} / F$ apparent volume of distribution during the terminal phase

$1986.5 \mathrm{ng} \mathrm{h} / \mathrm{mL}$ and $3526.0 \mathrm{ng} \mathrm{h} / \mathrm{mL}$ and $C_{\max }$ values of $227.7 \mathrm{ng} / \mathrm{mL}$ and $179.3 \mathrm{ng} / \mathrm{mL}$ in the 5-mg and 10-mg groups, respectively. Median $T_{\max }$ of the M-I metabolite was $3.0 \mathrm{~h}$ (range 2.9-3.0 h) and $6.0 \mathrm{~h}$ (range 1.0-6.0 h) in the $5-\mathrm{mg}$ and 10-mg groups, respectively, and mean $T_{1 / 2}$ was $5.4 \mathrm{~h}$ and $5.9 \mathrm{~h}$ in the $5-$ and $10-\mathrm{mg}$ groups, respectively. Median $T_{\max }$ of M-II was $5.9 \mathrm{~h}$ (range $4.0-6.0$ ) in the $5-\mathrm{mg}$ group and $8.0 \mathrm{~h}$ (range 6.0-24.1) in the 10-mg group; $T_{1 / 2}$ of M-II could only be calculated in one patient in the 5 -mg group (5.5 h).

Following a single oral dose, azilsartan and M-II were predominant moieties detected in the urine. The arithmetic mean cumulative urinary excretion ratios of azilsartan, M-I, M-II, and total at $24 \mathrm{~h}$ after a single oral administration of azilsartan $5 \mathrm{mg}$ were $6.6 \%, 0.1 \%, 13.5 \%$, and $20.3 \%$ of dose, respectively. The corresponding values for the $10-\mathrm{mg}$ dose group were $5.5 \%$, $0.0 \%, 8.2 \%$, and $13.7 \%$ of dose; however, the cumulative urinary excretion ratios of azilsar$\tan , \mathrm{M}-\mathrm{I}, \mathrm{M}-\mathrm{II}$, and total were very low for one patient in the $10-\mathrm{mg}$ group $(0.5 \%, 0.0 \%, 0.8 \%$, and $1.4 \%$ of dose, respectively) as a result of chronic renal disease that did not meet the exclusion criteria.

\section{Safety}

Only one patient in the 5-mg group experienced a TEAE, gastroenteritis, during the study. This was mild in severity and considered to be unrelated to the study drug. The outcome of the gastroenteritis was resolved. No deaths, serious TEAEs, or TEAEs leading to study drug discontinuation were reported during the study, and there were no findings of clinical concern from the clinical laboratory tests, or vital signs, physical examinations, and ECG assessments.

\section{DISCUSSION}

This study analyzed the pharmacokinetics and safety of a single 5- or 10-mg oral dose of azilsartan in six patients aged from 9 to 14 years with hypertension. To date, this is the first 
Japanese study of azilsartan pharmacokinetics in pediatric patients. The pharmacokinetic data indicate that azilsartan was rapidly absorbed following a single oral dose of 5 or $10 \mathrm{mg}$, with a respective median $T_{\max }$ for unchanged azilsar$\tan$ of 3.0 and $4.0 \mathrm{~h}$, and a mean $C_{\max }$ of 888.3 and $831.3 \mathrm{ng} / \mathrm{mL}$. After reaching $C_{\max }$ the plasma concentration of azilsartan decreased, with a mean $T_{1 / 2}$ of $4.7 \mathrm{~h}$ in the 5-mg group and $6.1 \mathrm{~h}$ in the 10-mg group. In the 5-mg and $10-\mathrm{mg}$ groups, mean azilsartan $\mathrm{AUC}_{(0-24)}$ was 6350.3 and $6871.7 \mathrm{ng} \mathrm{h} / \mathrm{mL}$, respectively, and mean $\mathrm{AUC}_{(0-\mathrm{inf})}$ was 6635.7 and $7433.3 \mathrm{ng} \mathrm{h} / \mathrm{mL}$. Only a small portion of the parent azilsartan molecule was excreted into urine.

In adults, as established in the azilsartan dose range of $10-40 \mathrm{mg}$ after single oral dosing, the mean $T_{\max }$ of unchanged azilsartan is $1.8-2.4 \mathrm{~h}$, mean $T_{1 / 2}$ is $12.8-13.2 \mathrm{~h}$, mean $C_{\max }$ is $1104.2-4707.8 \mathrm{ng} / \mathrm{mL}$, and mean $\mathrm{AUC}_{0-\mathrm{inf}}$ is 9055.3-33,892.0 $\mathrm{ng} \mathrm{h/mL} \mathrm{[9].} \mathrm{While} \mathrm{the} T_{1 / 2}$ of azilsartan appears to be much longer in adults than in children, this is likely due to differences in the pharmacokinetic evaluation periods: up to $72 \mathrm{~h}$ post-dose in adult studies compared with up to $24 \mathrm{~h}$ post-dose in the present pediatric study. In fact, our internal analysis based on the plasma concentration up to $24 \mathrm{~h}$ postdose demonstrated that $T_{1 / 2}$ was similar between adults and pediatric patients (data not shown). Our data show that, in pediatric patients, $T_{\max }$ was broadly in line with that reported for adults, while $C_{\max }$ and $\mathrm{AUC}_{0-\text { inf }}$ observed in this study were also similar to those observed in healthy adults at the 10-mg dose.

Azilsartan medoxomil, which is approved in the USA and Europe for the treatment of adult hypertension, is an ester prodrug that is rapidly and completely hydrolyzed to azilsartan-the bioactive moiety approved by the Pharmaceuticals and Medical Devices Agency in Japan-in the gastrointestinal tract during absorption, with no evidence for unchanged azilsartan medoxomil present in the plasma [17]. As the same active moiety enters the systemic circulation, the pharmacokinetic profiles of azilsartan and azilsartan medoxomil are regarded as being comparable. A phase 1 study by Webb and colleagues investigated the pharmacokinetics of azilsartan medoxomil in healthy adults and in children with hypertension aged 4 to 16 years [14]. Webb et al. developed a population pharmacokinetic model, which included the effect of body weight on CL/F and $V_{\mathrm{z}} / F$, to evaluate the applicability of the body weight-adjusted azilsartan medoxomil tablet doses used in pediatric patients in the weight ranges 8-25, $25-50$, and $50-100 \mathrm{~kg}$. According to their model-based simulations, pediatric patients with a body weight of 50-100 kg were expected to have similar azilsartan exposures to those of healthy adults at the same azilsartan medoxomil dose, and pediatric patients weighing 25-50 kg would have approximately double the exposure compared with adults at the same dose, with an acceptable safety profile [14]. The results of our study confirmed and validated those published by Webb et al., as exposure to $10 \mathrm{mg}$ azilsartan in pediatric patients weighing at least $50 \mathrm{~kg}$ was similar to that of $10 \mathrm{mg}$ azilsartan in healthy adults [9], and to that of $5 \mathrm{mg}$ azilsartan in pediatric patients weighing less than $50 \mathrm{~kg}$. Additionally, in our study, pediatric patients receiving the 5-mg dose had approximately $40 \%$ lower $\mathrm{CL} / F$ and $53 \%$ lower $V_{\mathrm{z}} / F$. Given that body weight is positively correlated with both volume of distribution and clearance [14, 18-22], this means both $\mathrm{CL} / F$ and $V_{\mathrm{z}} / F$ are lower in younger children (lighter body weight population) and is consistent with actual data obtained in our study. In terms of renal CL, no major difference was observed; this might be mainly because of the low ratio of renal CL to total CL.

The only TEAE reported in our study was a single incidence of gastroenteritis, which was mild in severity and considered to be unrelated to the study drug.

The main limitation of this pilot study is the small number of patients enrolled, which resulted in a limited pharmacokinetic estimation due to the limited range of body weights, and an insufficient safety evaluation. Furthermore, a single oral dose does not reflect the typical treatment course with antihypertensives, where patients are treated over a longer period of time. Although limited by the small number of patients and short treatment period, our results suggest that, similar to reported 
studies in adult patients $[5,6]$, azilsartan is well tolerated in pediatric patients.

\section{CONCLUSIONS}

In line with previous population PK data, our study suggests that pediatric patients weighing less than $50 \mathrm{~kg}$ may have approximately 2 -fold greater exposure to azilsartan than those weighing at least $50 \mathrm{~kg}$ at the same dose, whose exposure to azilsartan is comparable to that in healthy adults. Azilsartan treatment was feasible, with no unexpected safety signals observed in this study in pediatric patients with hypertension. A larger phase 3 study is ongoing to explore specific efficacy in this patient group.

\section{ACKNOWLEDGEMENTS}

The authors would like to thank the participants, and investigators and other staff members for their invaluable contributions to the study.

Funding. Sponsorship for this study, the open access fee and article processing charges were funded by Takeda Pharmaceutical Co. Ltd. All authors had full access to all of the data in this study and take complete responsibility for the integrity of the data and accuracy of the data analysis.

Medical Writing. The authors acknowledge Catherine Crookes of FireKite, an Ashfield company, part of UDG Healthcare plc, for writing support during the development of this manuscript, which was funded by Takeda Pharmaceutical Co. Ltd.

Authorship. All named authors meet the International Committee of Medical Journal Editors (ICMJE) criteria for authorship for this article, take responsibility for the integrity of the work as a whole, and have given their approval for this version to be published.

Disclosures. Kazuaki Enya is an employee of Takeda Pharmaceutical Co. Ltd. Hiroyuki
Okamoto was an employee of Takeda Pharmaceutical Co. Ltd. at the time of the study. Emiko Koumura is an employee of Takeda Pharmaceutical Co. Ltd. Takuya Kato was an employee of Takeda Pharmaceutical Co. Ltd. at the time of the study. Ben T. Saji was affiliated with an endowed department by BTS (Actelion Pharmaceuticals Japan Ltd.).

Compliance with Ethics Guidelines. Written, informed consent was received from the patients' parent/guardian and patients if possible before the start of the study. The study was conducted in compliance with the institutional review board (IRB) regulations stated in the Good Clinical Practice (GCP) guidelines, and all applicable local regulations. The ethical conduct of the study was in line with the Declaration of Helsinki and the International Conference on Harmonisation (ICH) Harmonised Tripartite Guideline for GCP E6, and all applicable laws and regulations. The protocol and other study-related documents were reviewed and approved by the IRB of the study site.

Data Availability. The data sets generated during and/or analyzed during the current study are not publicly available because this study is a small study and anonymization of the data is difficult to achieve.

Open Access. This article is distributed under the terms of the Creative Commons Attribution-NonCommercial 4.0 International License (http://creativecommons.org/licenses/ by-nc/4.0/), which permits any noncommercial use, distribution, and reproduction in any medium, provided you give appropriate credit to the original author(s) and the source, provide a link to the Creative Commons license, and indicate if changes were made.

\section{REFERENCES}

1. Shimamoto K, Ando K, Fujita T, et al. The Japanese society of hypertension guidelines for the management of hypertension (JSH 2014). Hypertens Res. 2014;37:253-390. 
2. Sorof JM, Lai D, Turner J, Poffenbarger T, Portman RJ. Overweight, ethnicity, and the prevalence of hypertension in school-aged children. Pediatrics. 2004;113:475-82.

3. International Pediatric Hypertension Association. Facts about patient populations. 2017. http://www. iphapediatrichypertension.org. Accessed 17 Jan 2017.

4. Falkner B. Hypertension in children and adolescents: epidemiology and natural history. Pediatr Nephrol. 2010;25:1219-24.

5. Rakugi H, Enya K, Sugiura K, Ikeda Y. Comparison of the efficacy and safety of azilsartan with that of candesartan cilexetil in Japanese patients with grade I-II essential hypertension: a randomized, double-blind clinical study. Hypertens Res. 2012;35:552-8.

6. Perez A, Cao C. Azilsartan in patients with mild to moderate hypertension using clinic and ambulatory blood pressure measurements. J Clin Hypertens. 2017;19:82-9.

7. Trachtman H, Hainer JW, Sugg J, et al. Efficacy, safety, and pharmacokinetics of candesartan cilexetil in hypertensive children aged 6 to 17 years. J Clin Hypertens (Greenwich). 2008;10:743-50.

8. Wells T, Blumer J, Meyers KE, et al. Effectiveness and safety of valsartan in children aged 6 to 16 years with hypertension. J Clin Hypertens (Greenwich). 2011;13:357-65.

9. Takeda Pharmaceutical Co. Ltd. Azilva tablet interview form [Japanese]. 2017. http://www.info.pmda. go.jp/go/interview/1/400256_2149048F1022_1_007_ 1F. Accessed 30 Apr 2018.

10. Perry CM. Azilsartan medoxomil: a review of its use in hypertension. Clin Drug Investig. 2012;32:621-39.

11. Preston RA, Karim A, Dudkowski C, et al. Singlecenter evaluation of the single-dose pharmacokinetics of the angiotensin II receptor antagonist azilsartan medoxomil in renal impairment. Clin Pharmacokinet. 2013;52:347-58.

12. Preston RA, Karim A, Garg D, Zhao C, Dudkowski C. Single-center phase I study of the single- and multiple-dose pharmacokinetics and safety of azilsartan medoxomil (AZL-M) in hepatic impairment (abstract no. PII-99). Clin Pharmacol Ther. 2012;91(Suppl 1):S89.

13. Zaiken K, Cheng JW. Azilsartan medoxomil: a new angiotensin receptor blocker. Clin Ther. 2011;33:1577-89.

14. Webb NJA, Wells T, Tsai M, Zhao Z, Juhasz A, Dudkowski C. Single-dose pharmacokinetics and safety of azilsartan medoxomil in children and adolescents with hypertension as compared to healthy adults. Eur J Clin Pharmacol. 2016;72:447-57.

15. JCS Joint Working Group. Guidelines for drug therapy in pediatric patients with cardiovascular diseases. 2013. http://www.jcircor.jp/guideline/ index.htm. Accessed 2017.

16. Kuze Y, Kogame A, Jinno F, Kondo T, Asahi S. Development, validation and application of the liquid chromatography tandem mass spectrometry method for simultaneous quantification of azilsartan medoxomil (TAK-491), azilsartan (TAK-536), and its 2 metabolites in human plasma. J Chromatogr B Analyt Technol Biomed Life Sci. 2015;1001:174-81.

17. Takeda Pharmaceutical Co. Ltd. Edarbi (azilsartan medoxomil) tablets: prescribing information. 2014. http://www.accessdata.fda.gov/drugsatfda_docs/ label/2014/200796s006lbl.pdf. Accessed 16 Feb 2017.

18. Anderson BJ, Holford NH. Mechanism-based concepts of size and maturity in pharmacokinetics. Annu Rev Pharmacol Toxicol. 2008;48:303-32.

19. Anderson BJ, Holford NH. Understanding dosing: children are small adults, neonates are immature children. Arch Dis Child. 2013;98:737-44.

20. Anderson BJ, Woollard GA, Holford NH. A model for size and age changes in the pharmacokinetics of paracetamol in neonates, infants and children. Br J Clin Pharmacol. 2000;50:125-34.

21. Tod M, Jullien V, Pons G. Facilitation of drug evaluation in children by population methods and modelling. Clin Pharmacokinet. 2008;47:231-43.

22. Tod M, Lokiec F, Bidault R, De Bony F, Petitjean O, Aujard Y. Pharmacokinetics of oral acyclovir in neonates and in infants: a population analysis. Antimicrob Agents Chemother. 2001;45:150-7. 